\title{
Hypertonic saline on brain relaxation during supratentorial tumor craniotomy: a dose-comparative study
}

Falcon-Araña $L^{*}$, Micol-Rodenas $\mathrm{JA}^{*}$, Fuentes-Garcia $\mathrm{D}^{\star}$, Ros-de-San-Pedro $\mathrm{J}^{\star *}$, Fernandez-Contreras $\mathbf{R}^{\star}$, Segura-Postigo $\mathbf{B}^{*}$

*: Dept of Anaesthesiology \& Pain Medicine, HCU Virgen de la Arrixaca, Murcia, Spain **: Dept of Neurosurgery, HCU Virgen de la Arrixaca, Murcia, Spain

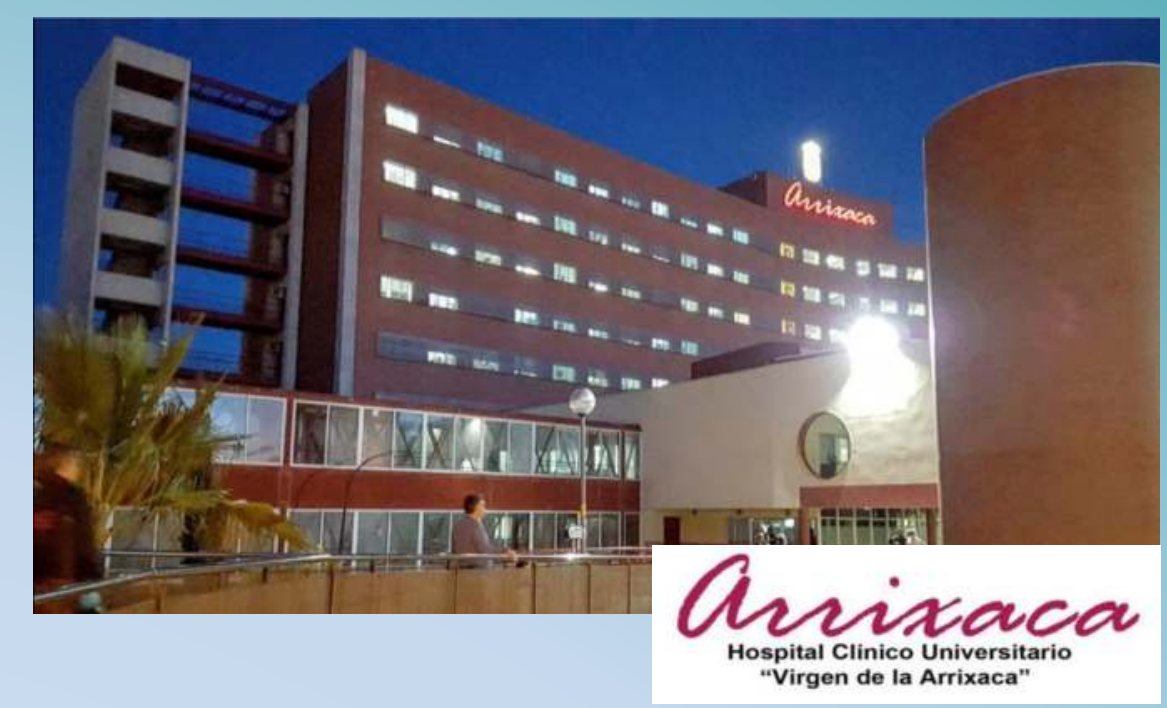

\section{BACKGROUND}

Evidence from RCTs suggest that hypertonic saline (HS) is at least as effective, if not better than mannitol for treatment of increased ICP. According to a recent meta-analysis comparing intraoperative effects of HS and mannitol in craniotomized patients, HS could significantly increase the odds of satisfactory intraoperative brain relaxation. No prospective studies stated a dose-response relationship of HS on brain relaxation in surgical setting. A prospective, randomized, double-blind study was designed to assess differences in brain relaxation between 2 doses of $3 \%$ HS during elective supratentorial brain tumor surgery.

\section{METHODS}

30 patients undergoing supratentorial craniotomy for tumor resection were enrolled to receive either $3 \mathrm{ml} / \mathrm{Kg}$ (group L) or 5 $\mathrm{ml} / \mathrm{Kg}$ (group $\mathrm{H}$ ) of $3 \% \mathrm{HS}$ administered at skin incision for 15 min. Brain relaxation was assessed after dura opening on a scale ranging 1-4 ( 1 = perfectly relaxed, $2=$ satisfactorily relaxed, $3=$ firm brain, $4=$ bulging brain). Hemodynamic variables, temperature, urine output, fluid balance, blood loss and laboratory values (blood gases, osmolality, hematocrit, glycaemia, lactate) were collected before HS infusion and 30 , 120 and 360 min after it. Head position, type and location of lesion, presence and magnitude of midline shift, extubating time, postoperative complications, ICU and hospital stay were also recorded as well as 30 day mortality.
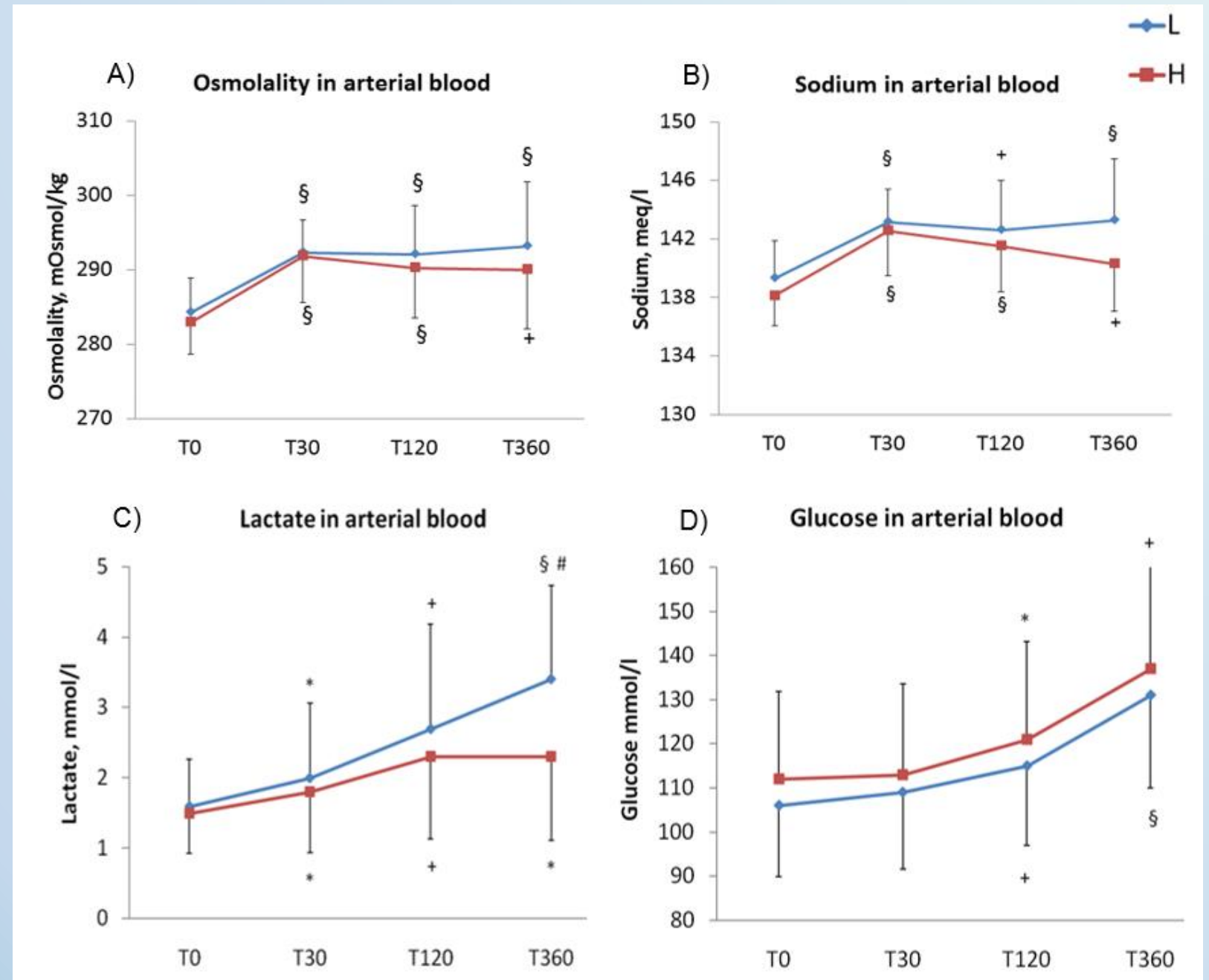

Fig.2. Osmolality (A), sodium (B), lactate (C) and glucose (D) in arterial blood. T0=time point immediately before infusion of the study drug : T30, T120, T360=time points 30, 120 and 360 $\mathrm{min}$, respectively after administration of the study drug. ${ }^{*} \mathrm{p}<0.05$ between groups; ${ }^{*} \mathrm{p}<0.05$, ${ }^{+} p<0.01$ and $\$ p<0.001$ compared with baseline (TO) $. L=3 \mathrm{ml} / \mathrm{k} \mathrm{HS}, \mathrm{H}=5 \mathrm{ml} / \mathrm{k} \mathrm{HS}$

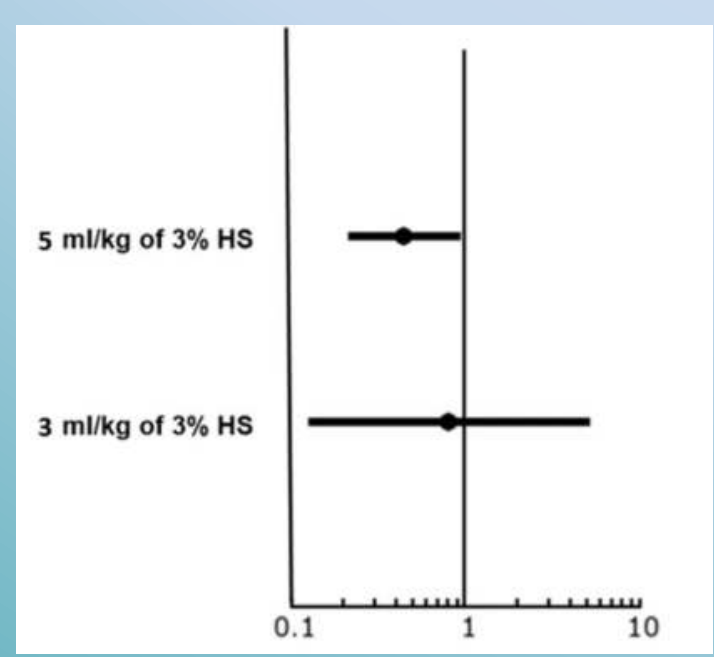

g. 3. Odds ratio for brain relaxation and midline shift. Higher dose of HS resulted in an odds ratio of 0.444 $(0.214-0.923)(P=0.057)$ and use of a lower dose resulted in an odds ratio of $0.800(0.126-5.092)(P=0.813)$.

\begin{tabular}{|c|c|c|c|}
\hline & $\begin{array}{l}\operatorname{L}(3 \mathrm{ml} / \mathrm{k} \mathrm{HS}) \\
(\mathrm{n}=15)\end{array}$ & $\begin{array}{c}H(5 \mathrm{ml} / \mathrm{k} \mathrm{HS}) \\
(n=15)\end{array}$ & $p$ value \\
\hline Age (yr) & $46 \pm 15$ & $51 \pm 15$ & 0.34 \\
\hline Male/Female & 10 (66.7 \%) / 5 (33.3 \%) & 10 (66.7 \%) / 5 (33.3 \%) & 1.00 \\
\hline BMI $\left(K G / m^{2}\right)$ & $26.5 \pm 2.3$ & $26.9 \pm 3.9$ & 0.67 \\
\hline ASA physical status II/III & 9 (60 \%) / 6 (40 \%) & 8 (53.3 \%) /7 (46.7 \%) & 0.71 \\
\hline $\begin{array}{l}\text { Fluid input at } 360 \mathrm{~min} \\
\text { (ml) }\end{array}$ & $4167 \pm 782$ & $3043 \pm 86$ & 0.07 \\
\hline $\begin{array}{l}\text { Urine output at } 360 \mathrm{~min} \\
\text { (ml) }\end{array}$ & $2035 \pm 904$ & $1334 \pm 546$ & 0.02 \\
\hline Balance (ml) & $1963 \pm 879$ & $1712 \pm 7183$ & 0.40 \\
\hline Surgery time (min) & $423 \pm 192$ & $325 \pm 158$ & 0.14 \\
\hline $\begin{array}{l}\text { Brain pathology, } \mathrm{n}(\%) \\
\text { Meningioma } \\
\text { Glioblastoma } \\
\text { Astrocitoma } \\
\text { Metastases }\end{array}$ & $\begin{array}{c}10(66 \%) \\
2(13 \%) \\
2(13 \%) \\
1(7 \%)\end{array}$ & $\begin{array}{c}9(60 \%) \\
4(26 \%) \\
2(13 \%) \\
0(0 \%)\end{array}$ & 0.63 \\
\hline Midline shift, n (\%) & 7 (46 \%) / 8 (54 \%) & 9 (61 \%) / 6 (39\%) & 0.36 \\
\hline
\end{tabular}

Yes /No

Table.1. Patients characteristics and surgical and anaesthetic data. Continous data are reported as mean $\pm S D$. Categorical data are given as $n(\%)$. ASA=American Society of Anaesthesiologists. $\mathrm{HS}=$ hypertonic saline; $\mathrm{BMI}=$ body mass index.

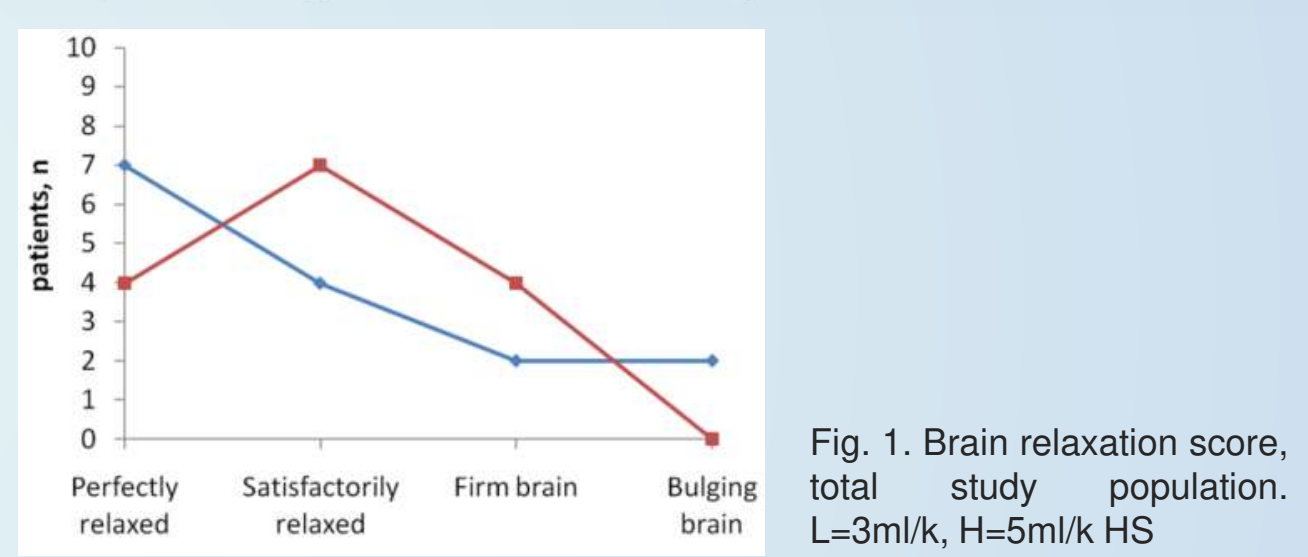

3. RESULTS

No significant differences between groups were found regarding age, gender, BMI and brain tumor location or size. In group $L 46$ $\%$ of patients (group $\mathrm{H}, 61 \%$ ) presented a midline shift $(P=0.362$ ). Median scores of brain relaxation (interquantile range) were $1.5(1-2.75)$ and $2.0(1.5-3)(P=0.211)$ for patients in groups $L$ and $H$, respectively. If adjusted for the presence of midline shift, the use of a higher dose of HS resulted in an odds ratio of $0.444(0.214-0.923)(P=0.057)$ and use of a lower dose resulted in $0.800(0.126-5.092)(P=0.813)$. So regarding effect of midline shift, relaxation score is not affected by the dose used of HS. No significant differences in postoperative complications and length of stay were observed.

\section{CONCLUSIONS}

$3 \mathrm{ml} / \mathrm{kg}$ of $3 \% \mathrm{HS}$ results in similar brain relaxation scores as 5 $\mathrm{ml} / \mathrm{kg}$ in patients undergoing craniotomy for supratentorial brain tumor. If adjusted for the presence of midline shift, patients in the higher dose group had not significantly differences in relaxation scores compared with the lower dose group.

Quentin $\mathrm{C}$ et al. A comparison of two doses of mannitol on brain relaxation during supratentorial brain tumor craniotomy: a randomized trial. Anesthandez-Palazón $\mathrm{J}$ et al $:$ a . A comparison of equivolume, equiosmolar solutions of hypertonic saline and mannitol for brain relaxation during LONDON, UK
28-30 MAY 2016 